\title{
EFEITO DESUPRESSOR DE POEIRANA MANIPULAÇÃO DE ROCHA FOSFÁTICA BAYÓVAR
}

\author{
L.L. CARVALHO ${ }^{(1)}$, T.S.CARRIJO ${ }^{(2)}$ e H.M. HENRIQUE ${ }^{(3)}$ \\ Universidade Federal de Uberlândia, Faculdade de EngenhariaQuímica \\ E-mail para contato: ${ }^{(1)}$ leonardocarvalho.equi.ufu@gmail.com, ${ }^{(2)}$ taynacarrijo@hotmail.com e \\ ${ }^{(3)}$ humberto@ufu.br
}

RESUMO - Com a crescente procura de fertilizantes, o consumo de fosfato aumentou no mercado brasileiro, ocasionando a necessidade de fontes alternativas. Nesse panorama, o fosfato reativo da rocha Bayóvar ganhou destaque no mercado por apresentar excelentes propriedades químicas a baixo custo como fonte de fosfato. Em contrapartida, devido à sua granulometria, o fosfato se dispersa facilmente no ar, ocasionando problemas respiratórios, prejuízo econômico e problemas ambientais. Com objetivo de diminuir a dispersão do material fosfatado em sua manipulação, este trabalho tem como propósito testar um supressor de poeira (antidust) para materiais que não sejam granulados e que geram partículas em suspensão no ar. Desta forma, avaliou-se resultados qualitativos da aplicação direta do produto (antidust) no material particulado, mostrando-se uma técnica eficaz.

\section{INTRODUÇÃO}

O setor agropecuário brasileiro encontra-se em crescimento. Segundo a Confederação da Agricultura e Pecuária do Brasil (CNA), a agropecuária brasileira apresentou em 2014 uma participação de 21,4\% no PIB (Produto Interno Bruto). Em 2015, o setor já representava 23\% da economia registrada em 2014. Para 2016, espera-se que haja o crescimento de $2,4 \%$ no setor (CNA, 2015). Ressalta-se que este setor apresenta índices consideráveis de crescimento desde a década de 90, época em que a contribuição era de apenas 1\% do PIB (IBGE, 1999).

Tamanha expansão na agropecuária brasileira exigiu o crescimento de outros setores. $\mathrm{O}$ consumo total de NPK (Nitrogênio, Fósforo e Potássio) passou de 990 mil toneladas em 1990 para 30 milhões de toneladas em 2014. O consumo de fósforo, neste mesmo período de 1990 a 2014 , teve um crescimento de $440 \%$ (IPNI, 2015). Visto que a deficiência de fósforo limita o crescimento das plantas e influi na produtividade e qualidade das culturas, ele torna-se essencial (MESQUITA et al., 2004).

Diante deste aumento exacerbado no consumo de fósforo, houve a necessidade de buscar outras fontes mais eficientes e economicamente viáveis. Com isto, o fosfato reativo de Bayóvar encontrado no Peru ganhou mercado. Este fosfato reativo apresenta maior velocidade de reação no solo, devido o maior grau de substituição isomórfica do íon fosfato por 
carbonato, solubilidade intermediária e menor custo por unidade de fósforo (NOVAIS etal.,2007).

Outra característica importante do fosfato de Bayóvar é seu peso específico e sua maior área superficial que o torna mais facilmente hidrolisado (PERUZZO; PÖTTKER; WIETHÖLTER, 1997). No entanto, a fina granulometria exigida para uma determinada reatividade faz com que o fosfato se disperse facilmente no ambiente durante o momento do carregamento e descarregamento de navios para sua exportação. Esta dispersão do material no ar e na água tem ocasionado problemas de eutrofização na Baía de Sechura no Peru, acarretando não só um desequilíbrio marinho, mas, também, um declínio na economia, visto que grande parte da renda da população local é gerada pela pesca. Além dos problemas respiratórios que podem ser causados nos trabalhadores e na população que vive próxima ao porto.

Visando adequar um supressor de poeira para material pulverulento e assim diminuir a dispersão de partículas no ar, o presente trabalho tem como objetivo avaliar qualitativamente a ação de um supressor de poeira (antidust) no material particulado. Sabido que, até o presente momento, há muitos estudos para supressão de poeiras em materiais granulados,não há indícios na literatura de trabalhos realizados de supressão de poeiras em materiais pulverulentos. Assim, este estudo busca o teste de um supressor de poeira que seja eficiente em partículas finas.

\section{MATERIAIS E MÉTODOS}

\subsection{Materiais}

O supressor de poeira utilizado tem nome comercial ANTIDUST G70 e foi desenvolvido pela empresa $H M X$ ChemicalSpecialties. Os outros materiais foram água e rocha Bayóvar. Para aspergir o supressor de poeira foi empregado um pulverizador e o mesmo foi aplicado sobre a rocha em um misturador rotativo de $120 \mathrm{~L}$ de capacidade.

\subsection{Métodos}

Elaboração do Antidust G70:O supressor G70 como fornecido pela empresa foi diluído a 70\% em massa com água. A figura 1 retrata o aspecto e a consistência do antidust G70 após diluição. 
Figura 1 - Aspecto e consistência do antidust G70

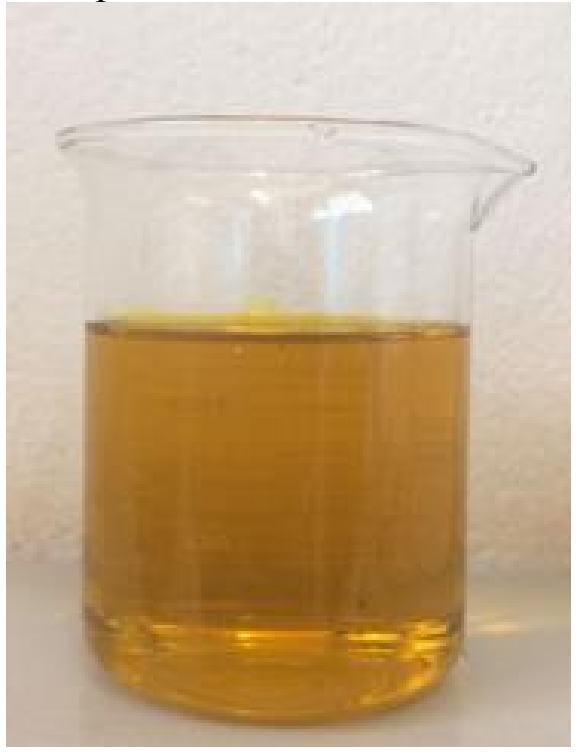

Aplicação do Antidust G70 na rocha Bayóvar:Adicionou-se inicialmente $5 \mathrm{~kg}$ de rocha no misturador e observou-se a formação de poeira (particulados finos em suspensão) no ar gerada. Posteriormente, utilizando-se de um pulverizador, aspergiu-se o antidust G70 até que os particulados finos desaparecessem.

Obtendo essa quantidade máxima aspergida, foram realizados testes variando proporcionalmente a quantidade do supressor de poeira (G70), de forma a não alterar as propriedades químicas e tampouco ocorrer aglomeração do material fosfático.

Para cada aplicação do aditivo G70, foram retirados $1,00 \mathrm{~kg}$ da rocha do misturador para análise. À vista disso, foram calculados balanços de massa para realização de nova aplicação do supressor de poeira.

\section{RESULTADOS E DISCUSSÃO}

A análise dos experimentos realizados limitou-se a uma avaliação qualitativa (visual) da quantidade de poeira gerada nos experimentos. Isso foi devido à inexistência de metodologia com validade para medição de geração de poeiras na manipulação de matérias pulverulenta. Há metodologia validada para quantificação de geração de poeiras na manipulação de fertilizantes granulares (grânulos de $1 \mathrm{~mm}$ a $4 \mathrm{~mm}$ de diâmetro). No momento os autores trabalham no desenvolvimento de metodologia para esse fim, com métodos que se baseiam em medidas de difração de raios infravermelho e um software que decodifica os resultados (Scandoleira, 2012).

Desta forma, com base no planejamento experimental, os resultados obtidos foram quantificados na Tabela 1. 
Tabela 1 - Razão aditivo G70 por tonelada de rocha fosfática

\begin{tabular}{cccc}
\hline Experimento & Rocha $\mathbf{( k g )}$ & $\mathbf{G 7 0} \mathbf{( g )}$ & $\mathbf{k g}$ de G70/t de rocha \\
\hline P1 & 5,00 & 49,80 & 9,96 \\
P2 & 5,00 & 10,50 & 2,10 \\
P3 & 4,00 & 16,53 & 4,13 \\
P4 & 3,00 & 18,47 & 6,16 \\
P5 & 2,00 & 17,09 & 8,55 \\
P6 & 1,00 & 10,65 & 10,65 \\
\hline
\end{tabular}

Inicialmente no experimento P1 estabeleceu a quantidade máxima a ser adicionada do aditivo G70, de forma que não alterasse significativamente as características físicas do material fosfático. Salientando-se que as propriedades de escoamento das partículas não deveriam ser afetadas, tampouco ocorresse o empelotamento das mesmas.

Com a máxima quantidade de aditivo G70 determinada, realizaram-se outros experimentos a fim de encontrar a menor razão ( $\mathrm{kg}$ de G70 por tonelada de rocha fosfática) que suprimisse visualmente a geração de poeira do material. Em comparação com a rocha fosfática in natura (sem adição de qualquer supressor de poeira) P2, P3 e P4 ainda apresentaram visualmente geração de poeira.Já o experimento P5 apresentou índices visuais quase nulos de poeira, sendo este, o mais viável para uma aplicação em grande escala. Conforme pode ser observado na Figura 1 (sem aplicação do G70) e na Figura 2 (razão 8,55 $\mathrm{kg}$ de G70/t de rocha).

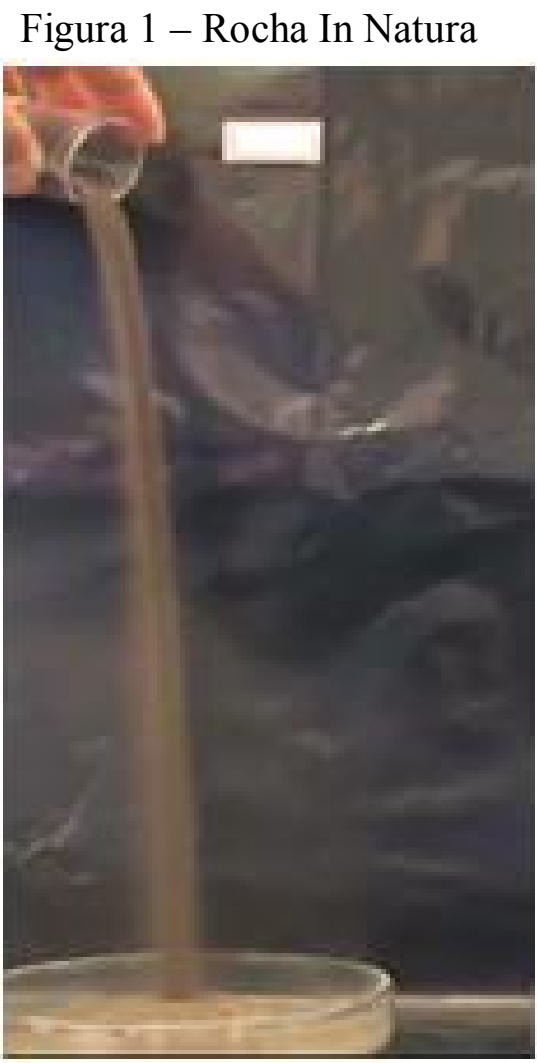

Figura 2 - G70 na razão de $8,55 \mathrm{~kg} / \mathrm{t}$

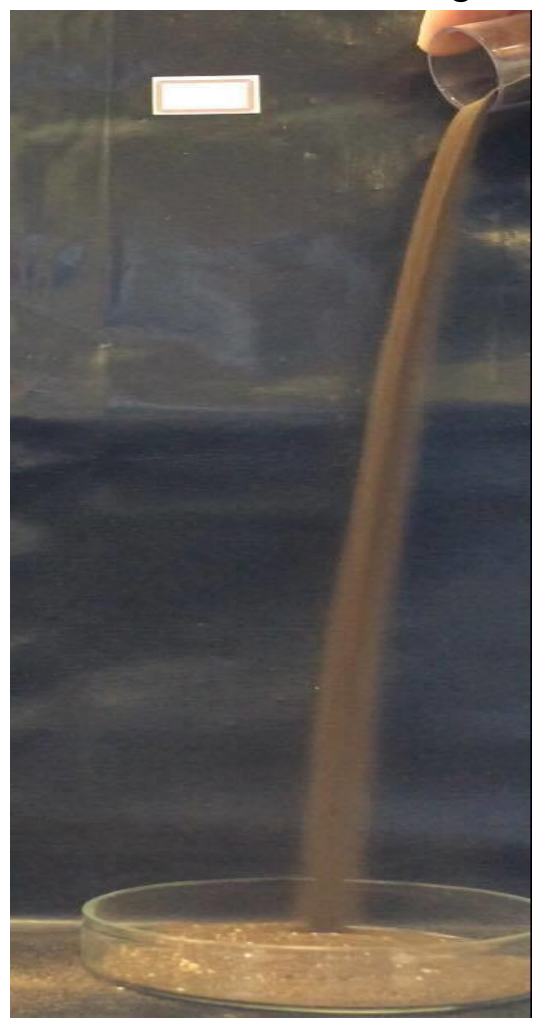


A razão de $8,55 \mathrm{~kg}$ do aditivo $\mathrm{G} 70$ para cada tonelada de rocha fosfática (P5) despontou-se devido às vantagens apresentadas: reduziram consideravelmente os índices visuais de poeira do materialtornando-os quase nulos, as características físicas foram mantidase não se observaram grandes alterações nas propriedades de escoamento da rocha.

Portanto, o antidust G70 mostrou-se eficiente na supressão de poeiras em partículas sólidas em suspensão no ar. Abrindo caminho para trabalhos futuros, em que seja possível quantificar a diminuição de poeiras e até mesmo, sua eficácia em fertilizantes que sejam pó. A utilização desse aditivo tem potencial de reduzir os problemas de eutrofização subsequentes da dispersão da rocha no ar e na água no momento da embarcação nos navios, evitando desequilíbrio marinho. Haverá diminuição significativa de quantidade de rocha desperdiçada, haja vista a quantidade de particulados finos gerados durante a transferência do material de navios para caminhões. Por consequência, haverá também a diminuição de problemas respiratórios dos moradores da região e dos trabalhadores.

\section{CONCLUSÃ̃}

Com base no método experimental, o antidust G70 revelou-se um material bastante eficaz para supressão de particulados finos da rocha Bayóvar. Observando a quantidade ideal de supressor de poeira utilizado por tonelada de rocha, conclui-se que há também viabilidade econômica. Devido à insuficiência de métodos analíticos para medição de poeiras em material pulverulento, a análise baseou-se observações visuais. Entretanto, evidenciou-se que as características físicas do material rochoso foram mantidas, não observando alterações significativas no escoamento da rocha, tampouco empelotamento.

Devido aos resultados satisfatórios, a utilização do antidust G70 como supressor de particulados finos de rocha, inicia um novo campo de pesquisa para trabalhos futuros, variando-se a composição química no supressor ou até mesmo misturando como outros reagentes.

\section{AGRADECIMENTOS}

Os autores agradecem a empresa HMX ChemicalSpecialtiesLtda pelo fornecimento de amostras de supressor de poeiras (G70).

\section{REFERÊNCIAS BIBLIOGRÁFICAS}

CHAGAS, W.F.T., Eficiência agronômica do fosfato reativo de Bayóvar associado ou não à calagem no cultivo do capim-piatã. 2013. 80 p. Dissertação. UFLA. Lavras, MG. 2013.

CNA-Banco de Dados, 2015.

IBGE- Banco de Dados, 1999. 
IPNI-Banco de Dados, 2015.

MESQUITA, E. E. et al. Teores críticos de fósforo em três solos para o estabelecimento de capim-mombaça, capim-marandu e capim-andrpogon em vasos. Revista Brasileira de Zootecnia, Viçosa, v. 33, n. 2, p. 290-301, 2004.

NOVAIS, R. F. et al. (Org.). Fertilidade do solo. Viçosa: Sociedade Brasileira de Ciência do Solo, 2007.

PERUZZO, G.; PÖTTKER, D.; WIETHÖLTER, S. Avaliação da eficiência agronômica dos fosfatos naturais reativos de Arad e de Gafsa. In: CONGRESSO BRASILEIRO DE CIÊNCIA DO SOLO, 26., 1997, Rio de Janeiro. Anais...Rio de Janeiro: SBCS, 1997. 1 CD-ROM.

SCANDOLEIRA, F.C., Desenvolvimento de método laboratorial de determinação de quantidade de particulados em suspensão no ar. 2012. 60p. Dissertação. USP. São Paulo, SP. 2012. 